\title{
Primary Pattern of Arteries of Upper Limb with Relevance to their Variations
}

\author{
Patrón Primario de las Arterias de los Miembros Superiores con Relevancia a sus Variaciones
}

\author{
"Suresh Bidarkotimath; ${ }^{* *}$ Ramakrishna Avadhani \& ${ }^{* * *}$ Arunachalam Kumar
}

BIDARKOTIMATH, S.; AVADHANI, R. \& ARUNACHALAM, K. Primary pattern of arteries of upper limb with relevance to their variations. Int. J. Morphol., 29(4):1422-1428, 2011.

SUMMARY: A detailed description of the vascular pattern of upper limbs especially their variations in their origin, course and branching pattern is of utmost importance anatomically in general and clinically in particular. These variations have drawn attention of surgeons, physicians, radiologists and interventionists due to the advanced surgical procedures practiced in vascular surgeries, plastic (reconstructive) surgeries and also for diagnostic and therapeutic approaches. 50 cadavers (100 upper limbs) were used for the study, which were dissected as the part of routine dissection for teaching undergraduate students at our institution. Length of the normal and variant arteries with mean, standard deviation, 'p' and ' $t$ ' values are noted in each of the limbs. The following variations are observed: i) high division of brachial artery, ii) higher origin of profunda brachii artery, iii) high origin of radial artery, iv) absence of common interosseous artery. The variations are of particular importance to the surgeons operating in the area, especially for those involved in vascular reconstructive surgeries. So it is prudent to do pre-operative studies of the brachial and antebrachial arteries and their branching patterns, to prevent possible complications post operatively. arteries.

KEY WORDS: Arterial variations in limbs; Brachial artery; Radial artery; Ulnar artery; interosseous artery; Accessory

\section{INTRODUCTION}

The earliest of the studies cited on morphology of the upper limb arterial variation pattern provide insufficient statistical data. On the other hand there have been controversies about the terminology, as some authors advised topographical names to the brachial and antebrachial arteries while others believed that the arterial variations should be individual entities. The existence of arterial variations in the upper limb was explained, based on findings from adult cadavers thinking that these variations represent the embryonic stage (Rodríguez-Baeza et al., 1995). Variations have been observed in the arterial patterns of the upper limb, where there is absence of brachial artery, radial artery, ulnar artery, and their branches. Also there may be difference in the origin of these arteries and their courses which may interfere with therapeutic, diagnostic and surgical procedures (McCormack et al., 1953). Recent study of anatomical variation testified the heterogenecity of our knowledge in this regard, where the median artery in the forearm is the point of study. It is reported that the incidence of variations ranges from $4.4 \%$ to $8.3 \%$ in various samples (Ozcan et al., 2006). Further they have included nonhomogeneous sample or incomplete extremities and have failed to describe the related morphological feature of each of the separate patterns, throughout their whole length in the arm and forearm (Içten et al., 1996).

Dimension of the brachial artery and flow-mediated dilatation (FMD) are associated with severity of cardiovascular diseases. Radial artery has been used for harvesting purpose in $(\mathrm{CABG})$ coronary artery bypass grafting (King, 2004). The radial forearm flaps are used in cosmetic surgeries, like for burns, contractures of neck, nasal reconstruction, correction of post-burn contractures of the neck and island flaps are used to replace soft tissue defects of the hand. Such flaps are also called as Chinese flap (Rodríguez-Niedenführ et al., 2000, 2001). The brachial and

\footnotetext{
*Assistant Professor, Department of Anatomy, A. J. Institute of Medical Sciences, Mangalore, India.

** Professor \& HOD, Department of Anatomy, Yenepoya Medical College, Mangalore, India.

*** Professor of Anatomy, K. S. Hegde Medical Academy, Mangalore, India.
} 
ante-brachial arteries are also the arteries of choice in treatment for chronic renal failure (CRF) for dialysis by making an autogenous fistula (Rodríguez-Niedenführ et al., 2001). While considering all these factors, study of vascular pattern of upper limb and its variations assume great importance to prevent and avoid possible complications and achieve best results after operations as well as therapeutic and diagnostic interventions. The present work is an attempt to study the origin, course, relation, variations and anomalies of brachial and ante brachial arteries in human cadavers.

\section{MATERIAL AND METHOD}

Fifty cadavers (100 limbs) were used during a routine dissection carried out at our institute. Longitudinal incision was taken through the deep fascia along the midline of arm and then brachial artery was identified and cleaned and its origin and branches were identified. Venae commitantes were identified and removed, variations were noted.

\section{RESULTS}

The following parameters were observed in both the right and left limbs. 1) length of the normal and variant arteries. 2) mean, standard deviation, 'p' and 't' values are noted. After statistical analysis the following were concluded: i) high division of brachial artery ii) higher origin of profunda brachii artery, iii) high origin of radial artery.

Measurements in male right and left upper limb.The length of the brachial artery varied between $23 \pm 8.64 \mathrm{~cm}$ $(p=0.819 ; t=0.233)$, radial artery between $22.99 \pm 3.03 \mathrm{~cm}$ $(\mathrm{p}=0.866 ; \mathrm{t}=0.172)$ and ulnar artery between $23.62 \pm 1.67(\mathrm{p}$ $=0.853 ; \mathrm{t}=0.18)$.

Measurements in female right and left upper limb.The lengths of the brachial artery varied between $22.65 \pm 0.77$ $\mathrm{cm}(\mathrm{p}=0.819, \mathrm{t}=0.233)$, radial artery varied between $21.74 \pm$ $0.53 \mathrm{~cm} .(\mathrm{p}=0.866, \mathrm{t}=0.172)$ and that of ulnar artery varied between $23.45 \pm 0.53 \mathrm{~cm} .(\mathrm{p}=0.853, \mathrm{t}=0.188)$.

The values of point of origin of branches of brachial artery.

Male right and left side. The lengths of the profunda brachii artery varied between $1.42 \pm 0.84 \mathrm{~cm}(\mathrm{p}=0.281, \mathrm{t}=1.091)$, nutrient artery varied between $2.49 \pm 0.16 \mathrm{~cm}(\mathrm{p}=0.427$, $\mathrm{t}=0.801)$, the superior ulnar collateral artery varied between $10.79 \pm 0.25 \mathrm{~cm}(\mathrm{p}=0.566, \mathrm{t}=0.578)$ and that of inferior ulnar collateral artery varied between $15.79 \pm 0.23(\mathrm{p}=0.887$, $\mathrm{t}=0.143)$

Female right and left side. The profunda brachii artery $1.23 \pm 0.22 \mathrm{~cm}(\mathrm{p}=0.722, \mathrm{t}=0.363)$, the nutrient artery $2.23 \pm 0.11 \mathrm{~cm}(\mathrm{p}=1, \mathrm{t}=0)$, the superior ulnar collateral artery $10.75 \pm 0.18 \mathrm{~cm}(\mathrm{p}=0.827, \mathrm{t}=0.222)$, and that of inferior ulnar collateral artery $15.77 \pm 0.18 \mathrm{~cm}(\mathrm{p}=0.832, \mathrm{t}=0.216)$.

In all 50 cadavers, the brachial artery is a continuation of axillary artery at the lower border of teres major muscle. Higher division of the brachial artery is noted in 2 cases. In both the cadavers brachial artery bifurcated in the middle of the arm into radial and ulnar artery. Here the radial artery was seen passing superficial to the biceps brachii muscle slightly lateral to the bicipital aponeurosis, running along the lateral aspect of forearm, going directly towards the anatomical snuff box (Figs. 1 and 4). The ulnar artery taking a short course in the arm, entered forearm deep to the bicipital aponeurosis. In a male cadaver aged 57 years in the course of dissection of axillary region, it was observed that the profunda brachii artery, originated from the 3rd part of axillary artery and continued downwards between medial and lateral roots of median nerve (Fig. 2). This artery was seen to be in close contact with the subscapularis muscle in its initial part. In a 30 year old male cadaver it was observed that the radial artery was originating at a higher level, it measured $44.2 \mathrm{~cm}$ and originated from 2nd part of the axillary artery, medial to the medial root of median nerve descending downwards, obliquely in the front of the arm crossing the brachial artery lying superficial to it at the level of middle of the arm from medial to lateral side. Here the brachial

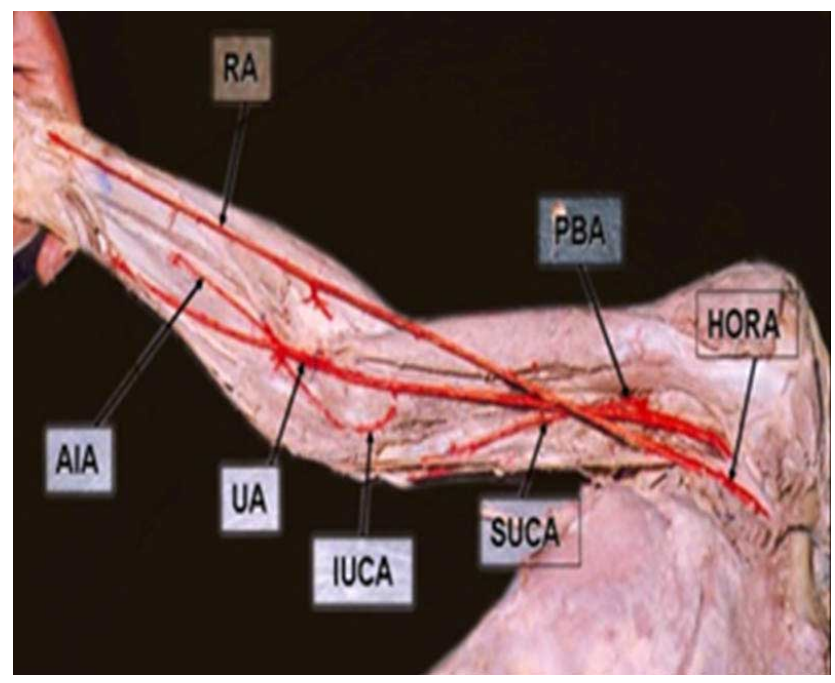

Fig. 1. High origin of radial artery in right upper limb. HORA = High origin of radial artery; PBA = Profunda brachii artery; SUCA $=$ Superior ulnar collateral artery; IUCA = Inferior ulnar collateral artery; RA = Radial artery; UA = Ulnar artery. 
artery continued as prominent ulnar artery. In a 55 year old male cadaver the common interosseous artery was absent, anterior interosseous artery was observed as a branch of ulnar artery and posterior as a direct branch of brachial artery.

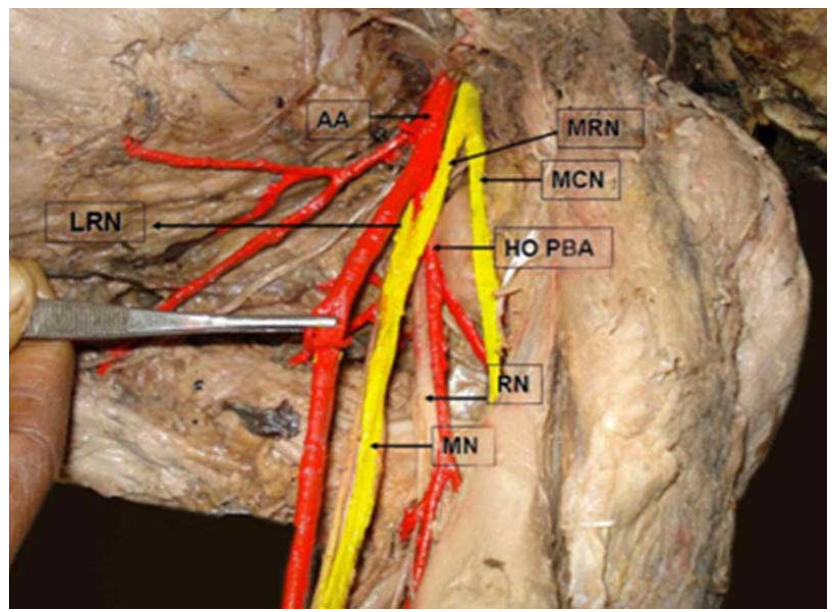

Fig. 2. $\mathrm{HOPBA}=$ High origin of brachial artery; $\mathrm{MRMN}=$ Medial root of median nerve; $\mathrm{LRN}=$ Lateral root of median nerve; $\mathrm{MCN}$ $=$ Musculocutaneous nerve $; \mathrm{AA}=$ Axillary nerve $; \mathrm{RN}=$ Radial nerve $; \mathrm{MN}=$ Median nerve

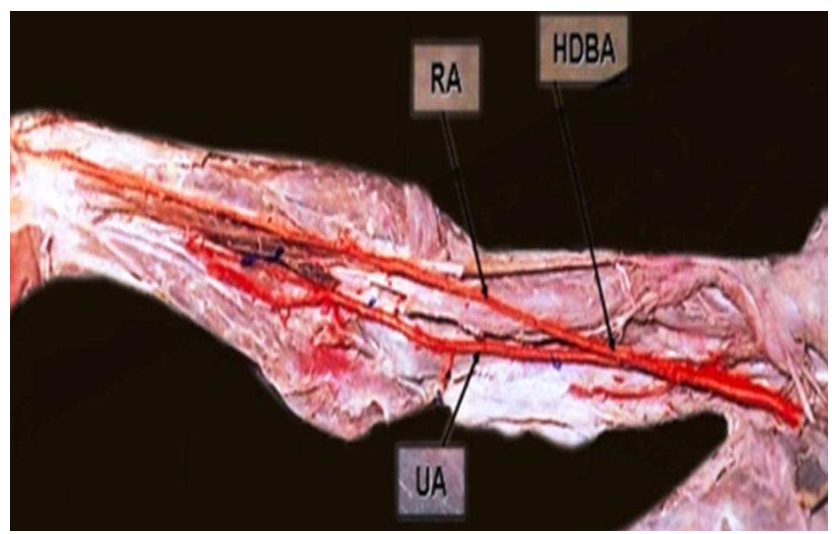

Fig. 3. High division of brachial artery. HDBA - High division of brachial artery; RA -Radial artery; UA-Ulnar artery.

\section{DISCUSSION}

Arterial variation in the upper limb was noted for the first time by von Haller in 1813. He made embryological studies on the variation of arterial pattern of upper limb but the exact findings were not obtained. The arteries develop from the axial trunk and extend from the axilla to the fingers. The proximal segment regresses to form the inactive adult pattern (Rodríguez-Baeza et al.). The anomalous blood vessels may be due to:

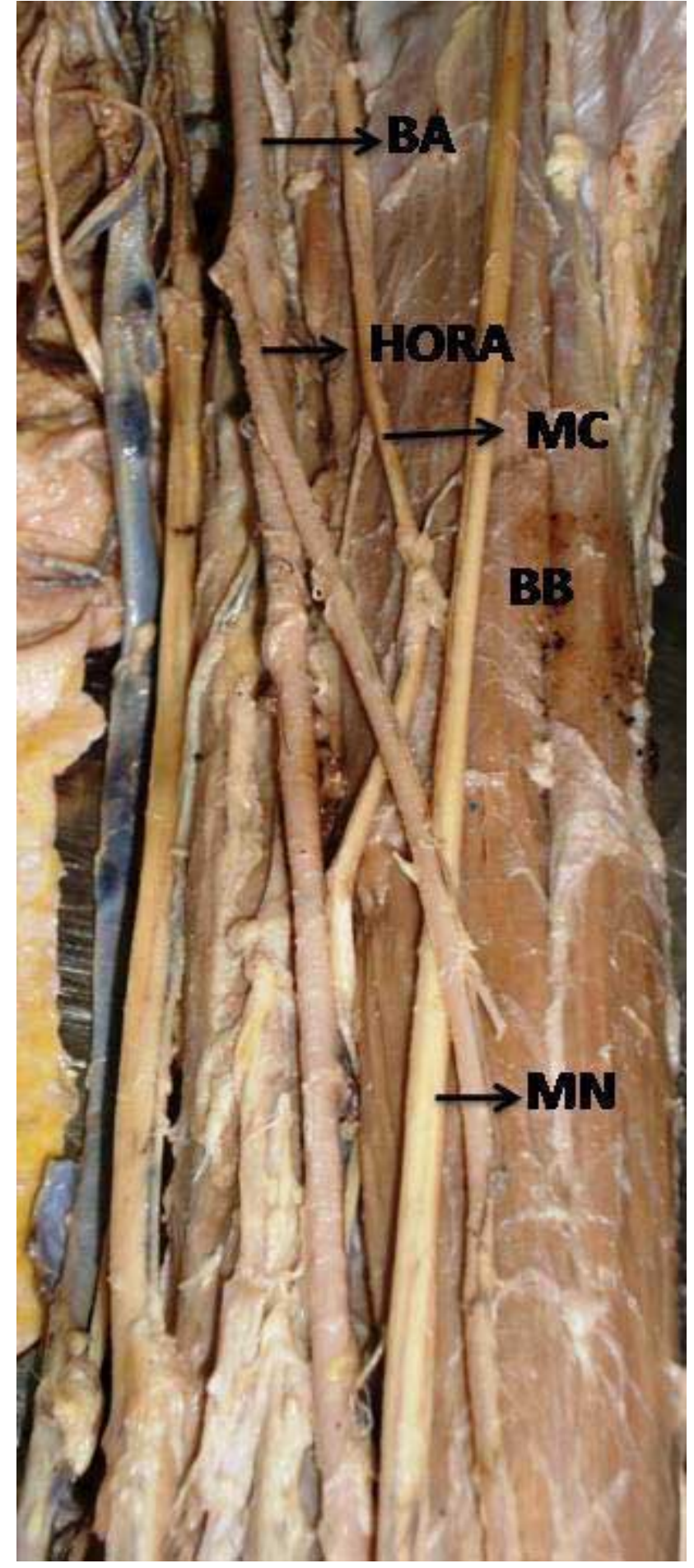

Fig. 4. HORA = High origin of radial artery, $\mathrm{MN}=$ Median nerve, $\mathrm{MC}=$ Musculocutaneous nerve, $\mathrm{BB}=$ Biceps brachii.

i) The choice of unusual paths in the primitive vascular plexuses.

ii) The presence of vessels that are normally obliterated.

iii)The disappearance of vessels that are normally retained. 
iv) Incomplete development.

v) Fusion and absorption of the parts which are usually distinct (Dorros \& Lewin, 1986).

McCoramack et al. dissected 750 cadavers and found variations in respect of origin and course of the arteries of upper limb, the percentage of variations noticed by them was $18.53 \%$. In this study bilateral variation occurred in $6.32 \%$, while in $24.45 \%$ there was unilateral variation. Most of these variations occurred more frequently on the right side by a ratio of 1.2:1, the variations of the axillary artery as compared with those of origin of brachial artery showed disparity. The variant vessels arising from left side of the axillary artery were found with a ratio of 3:1 (18 left and 6 right), while those from the brachial artery were found predominantly on the right side in a ratio of 1.5:1 (65 right and 43 left).

Series of variations are observed in the human brachioantebrachial arteries. The terminal branches of brachial artery in the cubital fossa shows two types of observations: (a) Bifurcation into ulnar artery and median-interosseus arterial trunk. (b) Three divisions of brachial artery: the ulnar artery, common interosseus artery and the median artery (RodríguezBaeza et al.). Duplication of the brachial artery also occurred, one superficial and another deep to the median nerve. In some, superficial brachial artery ended by anastomosing around the elbow joint; whereas in other it continues lower in antebrachial region (Rodríguez-Baeza et al.). It is the homologue of the superficial brachial artery observed in monkeys, others called it vasa aberrentia (Yoshinaga et al., 2003). Trifurcation of the brachial artery in left upper limb was observed, where the brachial artery gives ulnar, radial, and common interosseus arteries (Nakatani et al., 1997).

Structural and haemodynamic changes are observed in brachial artery by using Doppler ultrasound sonographic evaluation. This has been done in healthy individuals to know the diameter of the brachial artery and flow velocities. This is done before and after exercises. The following parameters were observed; i) Diameter of the artery. ii) Peak systolic maximum velocity. iii) End diastolic minimum velocity. iv) time averaged mean flow velocity. v) volume of blood flow. vi) flow wave form pattern. These measurements play an important role in haemodynamic mechanism during arm exercises. They noticed that arterial diameter did not significantly contribute to the increase in blood flow during moderate intensity exercises (Loukas \& Curry, 2006).

Dimension of the brachial artery and flow-mediated dilatation are associated with severe cardiovascular diseases due to numerous risk factors like advancing age, stress and strain. Non invasive brachial analysis has useful approach for detailed study of cardiovascular system and impact of cardiovascular diseases and other risk factors in population. Radial artery has been used for harvesting in cardiovascular diseases especially in coronary artery bypass grafting $(\mathrm{CABG})$ (King).

Classification of arm arterial variations.

I. Brachial artery passes in front of the median nerve and continues as:

Arteria brachialis superficialis superior.

Arteria brachialis inferior.

II. Double brachial artery i.e., superficial and deep:

A. Brachialis superficial superior.

B. Brachialis inferior:

1. Superficial and deep reunite.

2. Superficial continues as the radial:

a. without anastomosis.

b. with anastomosis.

3. Superficial brachial continues as

a. Ulnar b. Median c. Ulnar and Median

4. Superficial brachial as the radial and superficial antebrachial (Ozcan et al.)

The primitive axial artery and the superficial brachial artery have been implicated in the normal morphogenesis of the arteries of the upper limb. The axillary, brachial and interosseus arteries are derived from the primitive axial artery. Median artery arises as a branch of interosseus artery. This artery has a major haemodynamic function during SS III and SS IV (Singer's stage), and regresses at the SS V ( CS21) ( Carnegie's stage) remaining as a residual artery (RodríguezBaeza et al.).

Superficial brachial artery subdivides (found in $12.3 \%$ dissections) into three types:

- Those superficial brachial arteries which continue in cubital fossa and bifurcate as usual into radial and ulnar arteries $(3.6 \%)$.

- Superficial brachial artery continues as radial artery and known as "High origin of the radial artery" (5 to 9\%).

- Superficial brachial artery continues as ulnar artery and known as (2.8\%) "High origin of the ulnar artery" (Ozcan et al.)

In kinesiological study of the brachial artery dimensions, flow-mediated reactivity study are conducted to know the relative age related changes like dimensions, reactivity, and physical function. Research reveals an increase in resting Brachial Artery diameter with age up to approximately 65 years, after which change in diameter 
appears to reach plateau. The age-associated increase in resting Brachial Artery diameter may have been marked in the studies conducted in 19 out of 28 individuals, over the age of 80 years. The data obtained is compared with that of the mean Brachial Artery diameter in the study sample. In addition the peripheral resistance in arteriolar beds increases with age (King).

Profunda brachii artery: The profunda brachii (deep brachial) artery may arise from the third part of the axillary artery $(16 \%$, Anson in 1966, cited by Içten et al.) or in common with one or more branches of that vessel, (19\% of individuals, Poynter, cited by Içten et al.), or arise as a common trunk with superior ulnar collateral (22\%, Anson), axillary (16\%) or anterior and posterior (7\%, Anson) circumflex humeral artery (Içten $e t$ al.).

The origin of profunda brachii artery is quite variable. There are 7 types of origin for this artery.

Type I: Branch of brachial artery in $54.7 \%$ cases $(55 \%$ by Anson in 1966, cited by Nakatani et al., 1996).

Type Ia: Origin of arteria profunda brachii by 2 separate branches (seen in $0.7 \%$ dissections). Type Ib: Origin of arteria profunda brachii by 3 separate branches (seen in $0.3 \%$ dissections).

Type II: Arising as a common trunk with superior ulnar collateral in $22.3 \%$ cases ( $22 \%$ by Anson).

Type III: Arising at lower border of teres major so can be considered to be arising from axillary or brachial in $8 \%$ cases.

Type IV: Branch of 3rd part of axillary artery in $8.7 \%$ cases (16.0\% by Anson).

Type V: Arising as a common trunk with posterior circumflex humeral in $4 \%$ cases (13\% by Keen, 1961 and $7 \%$ by Anson, both cited by Nakatani et al.). Former includes $6 \%$ cases before entry of posterior circumflex humeral into quadrangular space and 7\% cases after its entry into quadrangular space (Nakatani et al.).

Type VI: Arising as a common trunk with subscapular and both circumflex humeral from axillary artery in $0.7 \%$ cases. Type VII: Absent arteria profunda brachii in $0.7 \%$ cases (Nakatani et al.).

Radial artery: Instances of the origin of the radial artery proximal to the intercondylar line formed the largest group of gross variations. Such variations were observed by McCormack et al. in 107 cadavers and the frequency is $14.27 \%$, of all specimens studied and $77 \%$ of all variations. Out of this group 16 variations arise from axillary artery (2.13\% of total $11.5 \%$ of variations) whereas 91 arise from some part of the brachial artery (12.14\% of total, $65.5 \%$ of variations).
The variations of radial artery are into 2 groups:

Type I: Variant which is more common involves a single dorsal division and is entirely superficial as in the case described by Gruber in 1870 (Cited by Wood et al., 1996).

Type II: Dorsal division further dividing into 2 branches, superficial and deep, as described by Quain in 1844 (Cited by Wood et al., 1996).

On the basis of type of anastomotic connection without reference to the point of origin, the radial artery is divided into four groups:

Group I: The radial artery has no significant gross anastomosis with other major vessels in their course through the arm and forearm.

Group II: Anastomosis is established with the deep or regular brachial artery in the antecubital region, the communicating vessel in those passes anterior to the biceps tendon.

Group III: The radial artery anastomosis with brachial artery and passes posterior to the biceps tendon.

Group IV: The radial artery anastomosis with the median artery in the forearm (McCormack et al.).

In another variety an atypical radial artery (ARA) was found in routine dissection. The atypical radial artery was present in left upper limb of an 82 year old female cadaver. The second part of the axillary artery gave typical thoracoacromial trunk and a second branch that arose more distally. The atypical radial artery ran parallel to the brachial artery and terminated as the sole contribution to the deep palmar arterial arch and did not contribute to the superficial palmar arch. The radial artery arose from superficial brachial artery in $5 \%$ of cases (Loukas \& Curry).

High origin of radial artery was seen in approximately $12.5 \%$ of cases. Out of that only $0.2 \%$ of low origin of the radial artery was reported (Ozcan et al.). The absence of radial artery has been rarely reported with an estimated incidence of less than $0.03 \%$ (Poteat, 1986). The higher origin of the radial artery found by an author, wherein he noticed that radial artery originated from the medial side of the brachial artery at a higher level than usual, which was $16.7 \mathrm{~cm}$ below the coracoid process. Then the artery crossed over the brachial artery running to the lateral side and descended in front of the forearm over the aponeurosis of the biceps brachii muscle (Sargon et al., 1996). Atypical radial artery, which arose from the second part of the axillary artery; it gave typical thoracoacromial trunk and second branch more distally. This gave lateral thoracic artery proximally, and the thoracodorsal artery and a typical radial artery where it terminated as the sole contribution to the deep palmar arterial arch and not giving a branch to superficial palmar arch (Loukas \& Curry). 
Radial artery variations were observed in $9.6 \%$ patients who had undergone transradial coronary intervention (TRI), where ultrasonagraphy of the radial artery was performed prospectively in 115 patients selected to undergo elective TRI. They include 6 tortuous configurations (5.2\%), two stenoses $(1.7 \%)$; two hypoplasias $(1.7 \%)$ and one radioulnar loop $(0.9 \%)$. The hypoplastic radial arteries and the radioulnar loop were inaccessible for catheterization and coronary intervention was planned via the femoral artery (Yokoyama et al., 2000).

In recent advances the radial artery is used in reconstructive micro vascular surgeries and also in plastic surgeries. The Chinese forearm flap based on the radial artery is extremely versatile. The radial forearm flap is ideal for intraoral reconstruction, where a thin palpable predominantly hairless skin is used to replace oral mucosa. The forearm flap is fascio-cutaneos flap based on the radial artery. Venous drainage is provided by venae comitantes of the artery (Rodríguez-Niedenführ et al., 2000, 2001).

Ulnar artery: The argument would be postulated that the ulnar artery system was the second to develop likewise the superficial brachial-radial arteries. A superficial ulnar artery was first to develop and later anastomotic connections develop in the cubital fossa between the brachial and superficial-ulnar artery, after which the proximal part of the superficial artery degenerated or atrophied. The distal part of the ulnar artery is derived from the medial terminal branch of the anterior interosseus artery (Rodríguez-Baeza et al.).

The incidence of variations of superficial ulnar artery ranges from $0.6 \%$ to $9.4 \%$. High origin of superficial ulnar artery was observed, where the frequency of unilateral variations is higher than bilateral. In living persons, Hazlett postulated a presence of superficial ulnar artery in $2.7 \%$ cases out of 542 persons studied by inspiration and palpation method (Bozer et al., 2004).

The existence of superficial ulnar artery has been documented by various investigators. Weathersby (1956) found 3 cases in 451 upper limbs $(0.6 \%)$; Quain found 29 cases in 442 upper limbs (6.8\%); Rodriquez-Baeza et al. found 8 cases in 151 upper limbs $(5.3 \%)$; Nakatani et al. found that superficial ulnar artery in 150 upper limbs (0.7\%); Uglettia $\&$ Kadir (cited by Bozer et al.) found $1 \%$ by the angiographic method. Devansh reported the incidence of superficial ulnar artery in $9.2 \%$ during the elevation of radial flap and $9 \%$ in Indians (cited by Bozer et al.). In a separate study the ulnar and radial arteries were running superficial to superficial flexor group of muscle in $75 \%$ cases. In a rare case of variations of brachial artery the superficial ulnar artery originating from deep brachial artery was observed (Hollinshead, 1969;
Sadeghi et al., 1997). In living persons, Hazlett postulated a presence of superficial ulnar artery in $2.7 \%$ cases out of 542 persons studied by inspiration and palpation method (Bozer et al.).

In the present study the variations of brachial artery were found in three cases, which is $10 \%$ of the $60 \mathrm{limbs}$ dissected. The profunda brachii artery was arising from 3rd part of axillary artery, in one instance of $60 \mathrm{limbs}$ dissected $(1.6 \%)$ as followed according to Type IV, Type V, Type VI, classification (Nakatani et al.). The radial artery arising from 2nd part of axillary artery out of 60 limbs dissected (1.6\%).

\section{CONCLUSION}

In the present study, the values of length, point of origin of the arteries of right and left upper limbs were compared. On applying significant tests the values were found to be statistically significant. Structural and haemodynamic changes were observed in brachial artery by using Doppler ultrasound sonographic evaluation. We noticed that arterial diameter did not significantly contribute to the blood flow increase during moderate intensity exercises. In recent advances the radial artery is used in reconstructive micro vascular surgeries and also in plastic surgeries. The Chinese forearm flap based on the radial artery is extremely versatile. The radial forearm flap is ideal for intra-oral reconstruction to replace oral mucosa.

\section{BIDARKOTIMATH, S.; AVADHANI, R. \&} ARUNACHALAM, K. Patrón primario de las arterias de los miembros superiores con relevancia a sus variaciones. Int. J. Morphol., 29(4):1422-1428, 2011.

RESUMEN: Una descripción detallada del patrón vascular de los miembros superiores, especialmente sus variaciones en el origen, curso y patrón de ramificación son de suma importancia anatómica en general y clínica en particular. Estas variaciones han llamado la atención de los cirujanos, médicos, radiólogos e intervencionistas debido a los procedimientos quirúrgicos avanzados practicados en cirugía vascular, cirugía plástica (de reconstrucción) y también para los métodos diagnósticos y terapéuticos. 50 cadáveres (100 miembros superiores) se utilizaron para el estudio, los que fueron disecados como parte de una disección de rutina para la enseñanza de los estudiantes de pregrado en nuestra institución. La longitud de las arterias normales y variantes con su media, desviación estándar, valores "p" y “t” se observaron en cada uno de los miembros. Las siguientes variaciones se observaron: i) división alta de la arteria braquial, ii) origen alto de la arteria braquial profunda, iii) origen alto de la arteria radial, iv) ausencia de la arteria interósea común. Las variaciones son de particular importancia para los cirujanos que operan en la zona, especial- 
mente para quienes participan en cirugías de reconstrucción vascular. Por lo tanto, es prudente hacer estudios pre-operatorios de las arterias braquial y antebraquiales y sus patrones de ramificación, para evitar posibles complicaciones post-operatorias.

PALABRAS CLAVE: Variaciones arteriales en los miembros; Arteria braquial; Arteria radial; Arteria ulnar; Arteria interósea; Arterias accesorias.

\section{REFERENCES}

Bozer, C.; Ulucam, E. \& Kutoglu, T. A case of originated high superficial ulnar artery. Trakia Journal of Sciences, 2(3):70-3, 2004.

Dorros, G. \& Lewin, R. F. The brachial artery method to transluminal internal mammary artery angioplasty. Cathet. Cardiovasc. Diagn., 12(5):341-6, 1986.

Hollinshead, W. H. Anatomy for Surgeons. $2^{\text {nd }}$ Ed. New York, Harper and Row Publishers, 1969.

Içten, N.; Süllü, Y. \& Tuncer, I. Variant high-origin radial artery: a bilateral case. Surg. Radiol. Anat., 18(1):63-6, 1996.

King, C. M. Brachial artery dimensions, flow-mediated reactivity, and physical function in older adults. Master Tesis, Louisiana State University, 2004. Available in: http://etd.lsu.edu/docs/ available/etd-04142004-111444/

Loukas, M. \& Curry, B. A case of an atypical radial artery. Clin. Anat., 19(8):706-7, 2006.

McCormack, L. J.; Cauldwell, E. W. \& Anson, B. J. Brachial and antebrachial arterial patterns; a study of 750 extremities. Surg. Gynecol. Obstet., 96(1):43-54, 1953.

Nakatani, T.; Tanaka, S. \& Mizukami, S. Superficial brachial arteries observed in bilateral arms. Kaibogaku Zasshi, 71(4):308-12, 1996.

Nakatani, T.; Tanaka, S. \& Mizukami, S. Superficial brachial artery continuing as the common interosseous artery. J. Anat., 191(1):155-7, 1997

Ozcan, H.; Oztekin, P. S.; Zergerog `lu, A. M.; Ersöz, G.; Fiçicilar, H. \& Ustüner, E. Doppler ultrasound evaluation of the structural and hemodynamic changes in the brachial artery following two different exercise protocols. Diagn. Interv. Radiol., 12(2):804, 2006.

Poteat, W. L. Report of a rare human variation: absence of the radial artery. Anat. Rec., 214(1):89-95, 1986.

Rodríguez-Baeza, A.; Nebot, J.; Ferreira, B.; Reina, F.; Pérez, J.; Sañudo, J. R. \& Roig, M. An anatomical study and ontogenetic explanation of 23 cases with variations in the main pattern of the human brachio-antebrachial arteries. J. Anat., 187(Pt 2):473-9, 1995.

Rodríguez-Niedenführ, M.; Burton, G. J.; Deu, J. \& Sañudo, J. R. Development of the arterial pattern in the upper limb of staged human embryos: normal development and anatomic variations. J. Anat., 199(4):407-17, 2001.

Rodríguez-Niedenführ, M.; Sañudo, J. R.; Vázquez, T.; Nearn, L.; Logan, B. \& Parkin, I. Anastomosis at the level of the elbow joint connecting the deep, or normal, brachial artery with major arterial variations of the upper limb. J. Anat., 196(1):115-9, 2000 .

Sadeghi, H. M.; Siciliano, S. \& Reychler, H. The use of ulnar microvascular free flap as an emergency solution after a complication during radial forearm free-flap raising. A case report. Int. J. Oral Maxillofac. Surg., 26(4):287-9, 1997.

Sargon, M. F.; Tanyeli, E.; Sürücü, H. S.; Yazar, F. \& Arifog `lu, Y. A complicated variation of the upper extremity vascularisation. Kaibogaku Zasshi, 71(3):211-4, 1996.

Weathersby, H. T. Unusual variation of the ulnar artery. Anat. Rec., 124:245-8, 1956.

Wood, S. J.; Abrahams, P. H.; Sañudo, J. R. \& Ferreira, B. J. Bilateral superficial radial artery at the wrist associated with a radial origin of a unilateral median artery. J. Anat., 189(3):6913, 1996.

Yokoyama, N.; Takeshita, S.; Ochiai, M.; Koyama, Y.; Hoshino, S.; Isshiki, T. \& Sato, T. Anatomic variations of the radial artery in patients undergoing transradial coronary intervention. Catheter Cardiovasc. Interv., 49(4):357-62, 2000.

Yoshinaga, K.; Tanii, I. \& Kodama, K. Superficial brachial artery crossing over the ulnar and median nerves from posterior to anterior: embryological significance. Anat. Sci. Int., 78(3):17780, 2003.

Correspondence to:

Prof. Arunachalam Kumar, K. S.

Hegde Medical Academy

Mangalore 575018

INDIA

Email: ixedoc@sulekha.com

Received: $14-10-2010$

Accepted: 23-02-2011 